\title{
New method for determining faecal fat excretion in infancy
}

\author{
S V Beath, K D Willis, I M N Hooley, G A Brown`, D A Kelly, I W Booth
}

\begin{abstract}
Collecting complete, timed stool samples for the estimation of faecal fat from infants wearing nappies is difficult. A gravimetric method has been adapted by applying a chloroform/ methanol homophasic solvent system to extract lipids from whole soiled nappies. In a study of 22 collections in six infants, no stools were lost and the recovery of lipids was $96 \%$, with results similar to a reference titrimetric method. In addition to total fat, individual lipids were measured using gas-liquid chromatography. The method simplifies stool collection and analysis, is aesthetically more acceptable, and leads to reduced microbial hazards. It also allows the detailed study of excreted lipid species enabling the coefficient of absorption of dietary lipids of various chain lengths to be determined individually.

(Arch Dis Child 1993; 69: 138-140)
\end{abstract}

The determination of faecal fat excretion in infants and toddlers is an important investigative tool in clinical research, though it is no longer considered to have an essential role in clinical diagnosis. ${ }^{2}$ Until now, the investigation has consisted in scraping stools from nappy liners and subsequent saponification, acidification, extraction by petroleum ether, and titrimetric measurement, a method first described in 1949 by van de Kamer et al. ${ }^{3}$

This method is notoriously unpleasant. There are also practical problems, especially in infants who produce numerous small volume stools that are often semisolid. Retrieving the faeces from the nappy or from nappy liners inevitably leads to inaccuracies. For example, for one of our patients with biliary atresia, in whom faeces and nappies were processed separately, $48 \%$ of the total amount of lipids present were retained in the nappy. Infants with fat malabsorption secondary to cholestasis or pancreatic disease often produce liquid stools which soak into

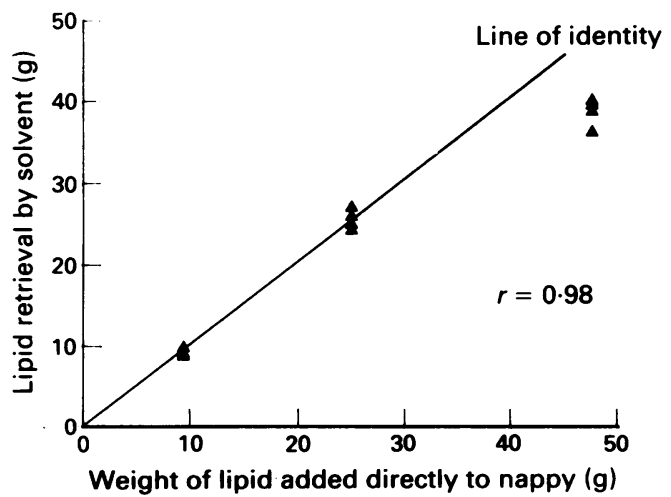

the nappy making retrieval impossible. It is precisely these infants in whom an accurate measurement of faecal fat excretion is often most desirable, especially if manipulations of dietary lipid or pancreatic enzyme supplementation are being made.

An alternative approach to the faecal fat estimation method of van de Kamer et $a l^{3}$ is a gravimetric method using a chloroform/ methanol homophasic solvent system to extract the lipids. ${ }^{45}$ We have adapted this method to enable faecal fat to be extracted from disposable nappies and have compared the results with the established titrimetric method. ${ }^{3}$

\section{Subjects and methods}

SUBJECTS

Twenty two 72 hour stool collections were performed on six infants aged 3-22 months with either biliary atresia (five infants) or Alagille's syndrome (one infant). All subjects had severe cholestasis and passed liquid stools most of the time. A food diary was kept and a paediatric dietitian calculated the fat intake for the 72 hours of collection.

\section{METHODS}

Stool collections

All soiled nappies used in 72 hours were saved. The plastic backing and dry part of the nappy were cut off and the soiled part weighed to estimate the stool and water content, then placed in a 31 sealed jar. A methanol/chloroform (AnalaR grade, $\mathrm{BDH}$, Poole) mixture in a ratio of $2: 1 \mathrm{vol} / \mathrm{vol}$ was added to the jar $(10 \mathrm{ml} / \mathrm{mg}$ soiled nappy). The optimum conditions for lipid extraction require the presence of 0.8 volume $0.05 \mathrm{M}$ hydrochloric acid $(\mathrm{HCl}) .^{46}$ The nappies, solvent, and acid were agitated together in a reciprocating bottle shaker (Harvard LTE, BDH 330/0002/00) for 30 minutes. A $400 \mathrm{ml}$ aliquot of extract was filtered using a 160 porosity filter funnel and water vacuum pump. A $95 \mathrm{ml}$ volume of the resulting translucent solution was subjected to phase separation by adding $62.5 \mathrm{ml} 0.05 \mathrm{M} \mathrm{HCl}$ and $25 \mathrm{ml}$ chloroform to a stoppered measuring cylinder. The extracted lipid was retained in the lower chloroform phase which had a volume of $45 \mathrm{ml}$. Duplicate $20 \mathrm{ml}$ aliquots from the lower phase were removed by aspiration and dispensed onto $10 \mathrm{~cm}$ weighed Petri dishes and left to evaporate at room temperature for four hours (the duration of evaporation was determined in validation experiments). The mass of the lipid residue was used to calculate the total mass of lipid contained in the original nappy collection as follows: total volume of chloroform/methanol solvent added to
Figure 1 Mass of lipids recovered from nappies by solvent extraction after the addition of a known weight of lipid emulsion.

\section{The Liver Unit, The $\star$ We regret the loss of Geoff Brown, who died}


nappy collection $=\mathrm{A} \mathrm{ml}$; volume of filtered extract subjected to phase separation $=B \mathrm{ml}$; volume of lower lipid phase left after phase separation $=\mathrm{C} \mathrm{ml}$; volume of lipid phase aliquot dispensed onto $10 \mathrm{~cm}$ Petri dish for evaporation $=\mathrm{D} \mathrm{ml}$; weight of lipid residue in Petri dish= E g.

$$
\text { Three day faecal fat excretion }(\mathrm{g})=\frac{\mathrm{ACE}}{\mathrm{BD}}
$$

\section{Gas-liquid chromatography}

The remaining $5 \mathrm{ml}$ of the lower chloroform phase were stored at $-20^{\circ} \mathrm{C}$ until analysed by gas-liquid chromatography. The lipids were extracted into heptane, methylated, and $1 \mu \mathrm{l}$ loaded onto a $1.5 \mathrm{~m}$ silica packed column (GP 10\% SP2330 Chromosorb WAW, Supelchem) and heated in a temperature gradient of $+4^{\circ} \mathrm{C} /$ minute over the range $150-220^{\circ} \mathrm{C}$. Chromatograms were produced by an integrator (Spectra Physics 4290) which calculated the relative areas of the peaks.

\section{Validation procedures}

The method was validated by several different experiments.

In separate experiments the recoveries of $1 \mathrm{~g}$ medium chain triglyceride oil (Scientific Hospital Supplies) and $1 \mathrm{~g}$ caprylic acid (C8:0, Sigma) added to chloroform/methanol solutions were assessed in duplicate.

The efficiency of the recovery of fats from nappies was tested by adding a $50 \%$ emulsion of equal volumes of Calogen (long chain triglycerides, Scientific Hospital Supplies) and Liquigen (medium chain triglycerides, Scientific Hospital Supplies) to a dry nappy. The nappy and lipid emulsion were subjected to agitation, filtration, phase separation, and evaporation as described under methods.

Various types of nappy (Peaudouce, Pampers, Ultratogs, Ultra (Boots)) were tested for extractable lipids. To assess the possible artefactual contribution of nappy creams, nappies which contained urine but no stools were processed after the application of the usual amount of nappy cream by parents.

Gravimetric and titrimetric (van de Kamer et $a l^{3}$ ) estimations were compared by subjecting the initial methanol/chloroform extract from nappies to either phase separation and evaporation or to saponification, acidification, extraction by petroleum ether, and alkali titration.

Medium chain triglyceride oils, oleic, linoleic, and linolenic acids were used as internal standards for the gas-liquid chromatography system.

\section{Results}

SUBJECTS

All collections were successful in a pilot study of six children with cholestatic liver disease in whom fat balance was studied serially.

\section{VALIDATION PROCEDURES}

Recovery of medium chain triglyceride oils from the lower chloroform phase was $96-108 \%$, even
Table 1 Mean $(S D)$ content of extractable lipids in various types of disposable nappies

\begin{tabular}{ll}
\hline Product name (4-9 kg size) & $\begin{array}{l}\text { Extractable lipids } \\
(\mathrm{g} / 100 \mathrm{~g} \text { nappy) }\end{array}$ \\
\hline Pampers & $0.52(0.01)$ \\
Peaudouce & $1.51(0 \cdot 14)$ \\
Ultra Togs & $0.48(0.02)$ \\
Ultra Child & $0.71(0.01)$ \\
\hline
\end{tabular}

Table 2 Amount of extractable lipids in wet (urine only) nappies and creams (single measurements)

\begin{tabular}{ll}
\hline Wet nappies and cream & $\begin{array}{l}\text { Extractable lipids } \\
\text { (g/nappy) }\end{array}$ \\
\hline E45 & $0 \cdot 35$ \\
Zinc and castor oil & $0 \cdot 43$ \\
Sudocream & $1 \cdot 26$ \\
\hline
\end{tabular}

after 44 hours of evaporation; there was no recovery from the upper polar phase. The evaporation of $20 \mathrm{ml}$ aliquots of lipid phase (that is, the chloroform carrier solution) containing caprylic acid was considered to be complete after four hours when a constant weight corresponding to $94-102 \%$ of the original mass was observed. The lipid residue was therefore weighed 4-44 hours after the start of evaporation.

The recoveries of $9 \cdot 35,25$, and $47 \cdot 5 \mathrm{~g}$ of lipids contained in the Liquigen and Calogen emulsion dispensed onto the nappies were respectively 97.75\% (range 93-104), 102\% (97-108), and $82 \%$ (77-85) (fig 1). The last recovery substantially underestimated the weight of lipid; this is not clinically relevant, however, as even grossly pathological stools do not yield $47 \cdot 5 \mathrm{~g}$ lipids in a single sample.

Unused nappies contained $0 \cdot 48-1.51 \mathrm{~g}$ lipid/ $100 \mathrm{~g}$ dry weight (table 1). Nappies which contained urine but no stools contained 0.35$1.26 \mathrm{~g}$ extractable lipids (table 2 ).

Figure 2 compares the gravimetric and van de Kamer et al titrimetric methods. ${ }^{3}$ The imprecision of the gravimetric method determined from the initial extract stage by duplicate analysis was $4.9 \%$. The two methods not only have a close correlation $(r=0.96)$ but the limits of agreement between the methods to two standard deviations was $-18 \mathrm{mg} / 20 \mathrm{ml}$ to $+56 \mathrm{mg} / 20 \mathrm{ml}$ solvent containing $700 \mathrm{mg}$ lipid (10\% or less). ${ }^{6}$ This difference is acceptable for clinical and research purposes.

Although medium chain triglycerides were

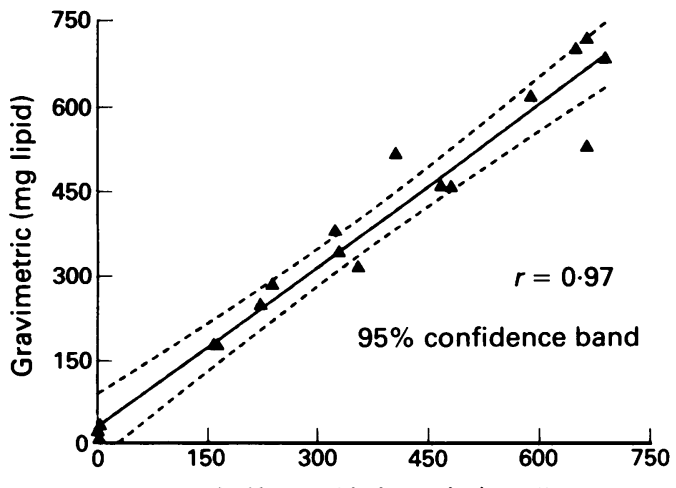

van de Kamer/titrimetric (mg lipid)

Figure 2 Mass of lipids recovered from nappies by the gravimetric and van de Kamer et $\mathrm{al}^{3}$ methods. 


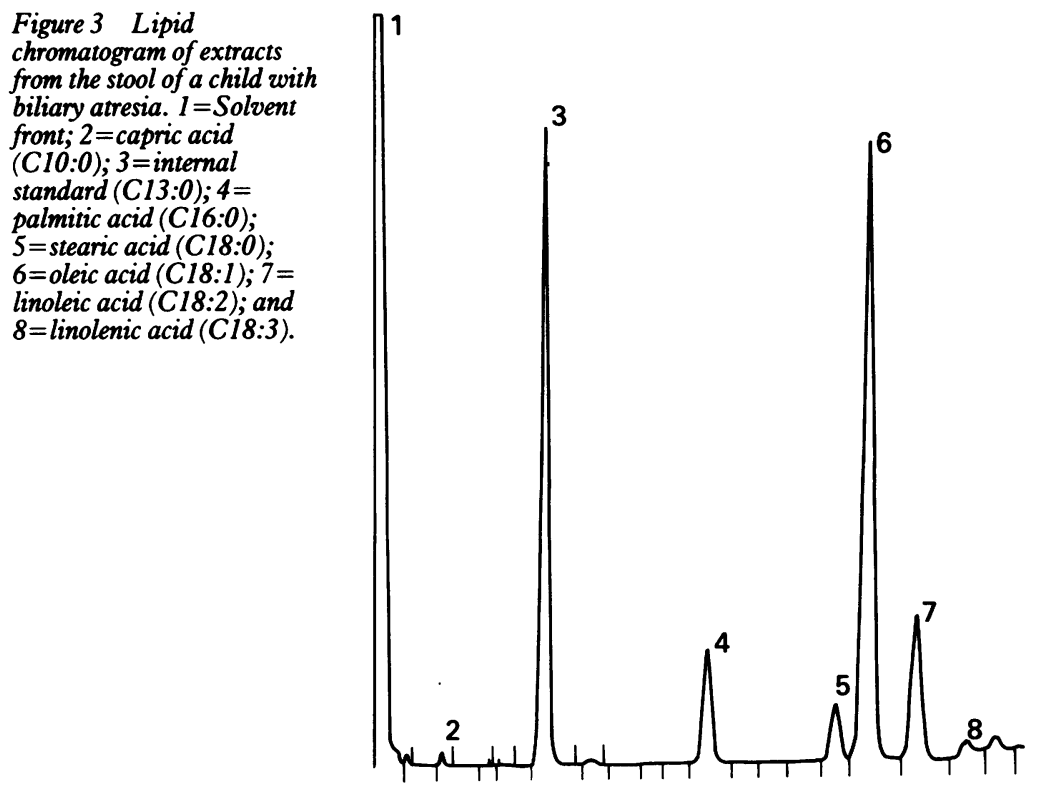

readily extracted by the gravimetric method (recovery $>90 \%$ ) and $38-56 \%$ of the injected lipids were detected by the gas-liquid chromatography system when validation runs were performed, almost none was present in faeces even when the subjects were receiving a diet rich in medium chain triglycerides $(5 \mathrm{~g} / \mathrm{kg} /$ day $)$. The predominant faecal lipids were oleic (C18:1) and linoleic (C18:2) acids, which are long chain fatty acids (fig 3).

\section{Discussion}

Previous descriptions of a gravimetric method based on solvent extraction of lipids did not attempt to use it to measure fat balance in infants, whose stools are virtually impossible to collect by conventional means. Before developing this novel method of faecal lipid extraction from soiled nappies, one third of attempted fat balances were unsuccessful because little or none of the faeces could be retrieved from the nappies or nappy liners of infants with liver disease. Since using a solvent system, however, a fat balance has been successfully completed in all infants studied.
Validation experiments showed that the solvent evaporated within four. hours and that even the more volatile medium chain triglycerides contained in the residual lipids were stable at room temperature for at least 44 hours. Despite their bulk, the nappies did not prevent the efficient extraction of lipids from the faeces, and the nappies themselves contributed less than $1 \%$ of the lipid detected. Solvent extraction of faecal fat from nappies was adaptable and acceptable to parents, nursing and technical staff, and compared favourably with the established reference method. ${ }^{3}$ A batch of six specimens took 24 hours to process and occupied a technician for approximately four hours.

The method has another advantage in that if qualitative and quantitative information on specific excreted lipid species are required ${ }^{7}$ an aliquot from the choloroform phase separation can be subjected to thin layer chromatography and gas-liquid chromatography.

This method of lipid extraction from whole nappies is extremely simple and can be set up rapidly. As fat malabsorption occurs in a wide range of clinical disorders ${ }^{1}$ the method has many applications, especially where there is a particular interest in optimising fat absorption and studying the pathophysiology of fat malabsorption.

We thank Scientific Hospital Supplies for providing laboratory consumables and The Children's Liver Foundation for funding technical support.

1 Anderson CM. Fat absorption and malabsorption. In: Brunser O, Carrazza FR, Nichols BL, Senterre J, eds. Clinical nutrition of the young child. New York: Raven Press, 1991: 175-93.

2 Anderson CM, Burke V, Gracey M, eds. Paediatric gastroenterology. 2nd Ed. London: Blackwell Scientific, 1987: $870-2$.

3 van de Kamer JH, den Bokkel Huinink H, Weyers HA. Rapid method for the determination of fat in faeces. 7 Biol Chem 1949; 177: 347-55.

4 Bligh EG, Dyer WJ. A rapid method of total lipid extraction and purification. Can 7 Physiol Pharmacol 1959; 37: 911-7.

5 Jeejeebhoy KN, Ahmad S, Kozak G. Determination of fecal fats containing both medium and long chain triglycerides and fats containing both medium and long chain

6 Bland JM, Altman DG. Statistical methods for assessing greement between two methods of clinical measurement. Lancet 1986; i: 307-10.

7 Ackman RG, Ratnayake WMN. Lipid analyses: part I. In: Vergroesen AJ, Crawford $M$, eds. The role of fats in human nutrition. London: Academic Press, 1989: 442-514. 